\title{
Dil ve konuşma terapisi öğrencilerinin gözünden aile merkezli hizmet
}

\author{
Viewpoints of speech and language therapy students on family-centered service
}

Pınar Zengin Akkuş, Tuğçe Karahan, Evin İlter Bahadur, Elif Nursel Özmert

\section{Öz}

Amaç: Çocuğun sağlığında ve gelişiminde ailenin önemi anlaşıldıkça, çocuk sağlığı hizmetinde, aile merkezli hizmet ideal yaklaşım olarak kabul edilmiştir. Uluslararası yazında eğitim sürecinde olan sağlık çalışanlarının aile merkezli hizmet (AMH) hakkındaki görüşlerini ve uygulamalarını değerlendiren çalışmalara rastlanırken ülkemizde bu konuda yapılmış çok kısıtlı sayıda araştırma bulunmaktadır. Bu çalışmada dil ve konuşma terapisi bölümünde eğitim alan öğrencilerin aile merkezli hizmet hakkında görüşlerinin ortaya konması ve aile merkezli uygulamalarının değerlendirilmesi planlanmıştır.

Gereç ve yöntem: Bu çalışmaya 84 öğrenci katıımıştır. Katılımcıların aile merkezli davranışlarını değerlendirmek amacıyla Hizmet Sağlayıcılar İçin Bakım Süreci Ölçeği ve AMH konusuna bakış açılarını ortaya koymak için Aile Merkezli Bakım Hakkında Görüşlerin Değerlendirilmesi Anketi kullanılmıştır.

Bulgular: Bu çalışmada dil ve konuşma terapisi alanında hizmet verecek olan öğrencilerin AMH'e bakış açıları ve aile merkezli uygulamaları sunulmuştur. Bu çalışmanın sonuçları, daha önce yayınlanmış benzer bir çalışma ile karşılaştırıldığında, dil ve konuşma terapisi bölümü öğrencilerinin, pediatri araştırma görevlilerine kıyasla, aile merkezli uygulamalarda kendilerini daha yüksek puanladıklarını, AMH ilkelerini daha çok benimsediklerini ve bu uygulamalar konusunda kendilerini daha yetkin ve bilgili hissettiklerini göstermektedir.

Sonuç: Bu çalışmanın sonuçları çocuk sağlığı ve erken müdahale alanında aile merkezli hizmetlerin yaygınlaşmasını hedefleyen eğitimciler, yöneticiler ve politika yapıcılar için yol gösterici olabilecektir.

Anahtar kelimeler: Dil ve konuşma terapisi, çocuk sağlığı hizmeti, aile merkezli hizmet, aile merkezli uygulamalar.

Zengin Akkuş $\mathrm{P}$, Karahan T, Bahadur El, Özmert EN. Dil ve konuşma terapisi öğrencilerinin gözünden aile merkezli hizmet. Pam Tıp Derg 2021;14:530-537.

\begin{abstract}
Purpose: As the important role of the family in the health and development of the child have been understood, family-centered service is acknowledged as the standard of care in pediatric health care. While there are studies in the literature focusing on the views of healthcare students about family-centered service (FCC), in our country, there are a limited number of studies investigating the views and family-centered practices of healthcare students. In this study, it was aimed to explore the viewpoints of students of the speech and language therapy department about family-centered service and to evaluate their family-centered practices.

Materials and methods: Eighty-four students were included. The Measure of Processes of Care for Service Providers was used to measure family-centeredness of participants and the Questionnaire to Evaluate Perceptions on FCC was utilized to understand perceptions and beliefs.

Results: This study presented the perspectives and family-centered practices of speech and language therapy students. It has been demonstrated that the speech and language therapy students have higher scores of family-centered practices, adopt the principles of FCC, and feel more competent and knowledgeable about family-centered practices compared to pediatrics residents in the same institution.

Conclusion: The results of this study may guide educators, managers, and policymakers who aim to spread family-centered services in early intervention services and pediatric health care.
\end{abstract}

Key words: Speech and language therapy, child health care, family-centered service, family-centered practices.

Zengin Akkus P, Karahan T, Bahadur El, Ozmert EN. Viewpoints of speech and language therapy students on family-centered service. Pam Med J 2021;14:530-537.

Pınar Zengin Akkuş, Uzm. Dr. Hacettepe Üniversitesi Tıp Fakültesi, Çocuk Sağığı ve Hastalıkları Anabilim Dalı, Gelişimsel Pediatri Bilim Dalı, Ankara, Türkiye, e-posta: pinarzenginakkus@gmail.com (https://orcid.org/0000-0003-1704-0327) (Sorumlu Yazar)

Tuğçe Karahan, Arş. Gör. Hacettepe Üniversitesi Sağlık Bilimleri Fakültesi, Dil ve Konuşma Terapisi Bölümü, Ankara, Türkiye, e-posta: karahantugce@gmail.com (https://orcid.org/0000-0001-5112-8977)

Evin İlter Bahadur, Uzm. Dr. Hacettepe Üniversitesi Tıp Fakültesi, Çocuk Sağlığı ve Hastalıkları Anabilim Dalı, Gelişimsel Pediatri Bilim Dalı, Ankara, Türkiye, e-posta: evinbahadur@gmail.com (https://orcid.org/0000-0003-0592-6710)

Elif Nursel Özmert, Prof. Dr. Hacettepe Üniversitesi Tıp Fakültesi, Çocuk Sağlığı ve Hastalıkları Anabilim Dalı, Gelişimsel Pediatri Bilim Dalı, Ankara, Türkiye, e-posta: elifnurselozmert@gmail.com (https://orcid.org/0000-0002-4911-9200) 


\section{Giriş}

Aile merkezli hizmet (AMH), sağlık hizmetinin her alanında, hasta ve ailesi ile sağlık çalışanları arasında, tarafların faydasını gözetecek şekilde işbirliği kurulması esasına dayanır [1]. Aile merkezli yaklaşım, aileyi, çocuğun güçlü yanı ve destek mekanizması olarak kabul eder ve çocuk ile ilgili karar alma sürecinde aileyi ön planda tutar [2].

Çocuğun sağlığında ve gelişiminde ailenin rolü anlaşılmaya başlandıkça, çocuk sağlığı hizmetinde aileye verilen önem artmıştır. Yapılan çalışmalarda aile merkezli uygulamaların, hasta ve ailesinin memnuniyetini arttırdığı gibi sağlık çalışanlarının da memnuniyetini arttırdığı, sağlık hizmetinin sonuçlarını iyileştirdiği, kaynakların daha iyi kullanımını sağladığı ve sağlık hizmeti harcamalarını azalttığı gösterilmiştir [2]. Benzer şekilde, erken müdahale hizmetlerinde de aile merkezli yaklaşımın benimsenmesinin, çocuğa, aileye, sağlık çalışanlarına ve sağlık sistemine sağladığı faydalara alan yazında genişçe yer verilmiştir [3, 4].

Aile merkezli yaklaşım ve sonuçları konusundaki yayınların artışıyla beraber, çocuk sağlığı hizmetinde 'çocuk odaklı' yaklaşımdan 'aile odaklı' yaklaşıma geçilmiş, terapi hizmetlerinde de aile merkezli uygulamalar hızla artmıştır [5]. Erken müdahale hizmetlerinde AMH ideal yaklaşım olarak kabul edilmiştir [6]. Dil ve konuşma terapisi terapisi alanında da, verilecek hizmetlerin aile merkezli olmasının ve çocuğun dil, konuşma, ses, yutma ve iletişim sorunlarına yapılacak müdahalelerin planlanması sürecine ailelerin dahil edilmesinin gerekliliği ve faydaları ortaya konmuştur [7].

Aile merkezli uygulamaların olumlu yönleriyle beraber, mevcut sağlık sistemlerine ve müdahale programlarına entegre edilmesinde yaşanan çeşitli zorluklara uluslararası yazında yer verilmiştir [8-10]. Erken müdahale alanında hizmet veren sağlık çalışanlarının yaşadığı zorluklara yer veren bir araştırmada, katılımcılar öğrencilik sürecinde aile merkezli uygulamalar için yeterli şekilde hazırlanmadıklarını ve deneyim kazanamadıklarını belirtmişlerdir [11].

Dünyada çocuk sağlığı hizmetinde, ideal yaklaşım aile merkezli yaklaşım olarak kabul edilmekle beraber, ülkemizde aile merkezli uygulamalar konusunda henüz yasal bir düzenleme yapılmamıştır. Aile merkezli yaklaşımın doğru şekilde uygulanabilmesi için önceliklesağlıkçalışanlarıtarafından anlaşılması ve benimsenmesi gerekmektedir. Bununla beraber sağlık çalışanlarının konu hakkındaki görüşlerinin öğrenilmesi ve uygulamalarının ne kadar aile merkezli olduğunun değerlendirilmesi de önem taşımaktadır. Uluslararası yazında eğitim sürecinde olan sağlık çalışanlarının aile merkezli hizmet hakkındaki görüşlerini araştıran çalışmalara rastlanırken [12-14], ülkemizde eğitim sürecinde olan sağlık çalışanlarının aile merkezli yaklaşım hakkında görüşlerini ortaya koyan ve aile merkezli uygulamalarını değerlendiren çok kısıtı sayıda araştırma bulunmaktadır [15]. Bu nedenle, bu çalışmada dil ve konuşma terapisi bölümünde eğitim alan ve aynı zamanda en az 6 aydır çocuk sağlığı alanında hizmet veren lisans, yüksek lisans ve doktora öğrencilerinin aile merkezli hizmet hakkında görüşlerinin değerlendirilmesi ve aile merkezli davranışlarının ölçülmesi planlanmıştır.

\section{Gereç ve yöntem}

Bu kesitsel çalışma Hacettepe Üniversitesi Tıp Fakültesi Çocuk Sağlığı ve Hastalıkları Anabilim Dalı Gelişimsel Pediatri Bilim Dalı ve Hacettepe Üniversitesi Sağlık Bilimleri Fakültesi Dil ve Konuşma Terapisi Bölümü tarafından yapılmıştır. $\mathrm{Bu}$ çalışma için Hacettepe Üniversitesi Etik Komisyonu'ndan izin alınmıştır.

$\mathrm{Bu}$ çalışmanın katılımcıları Hacettepe Üniversitesi Sağlık Bilimleri Fakültesi Dil ve Konuşma Terapisi Bölümü'nde lisans, yüksek lisans ve doktora eğitimlerini sürdüren öğrencilerden oluşmaktadır. Çalışmaya Dil ve Konuşma Terapisi lisans eğitiminin son yılında olup, 6 aydır mesleki uygulama dersleri kapsamında sorumlu öğretim üyesi gözetiminde dil ve konuşma terapisi yapmakta olan öğrenciler ile yüksek lisans/doktora öğrencileri davet edilmiştir. Yapılan güç analizi sonucunda, \%80 güç ve $\% 5$ lik bir hata düzeyinde bir tasarım için, araştırmaya 80 katıımcının dâhil edilmesi hedeflenmiştir. Çalışma hakkında detaylı bilgi verildikten sonra, toplam 86 öğrenciden çalışmaya katılmayı kabul eden 84 öğrenci (52 lisans ve 32 yüksek lisans/doktora öğrencisi) çalışmaya dahil edilmiştir. Katılımcılardan isim bilgisi alınmamıştır. Katııımcıların cinsiyetleri ve alandaki deneyim süreleri sorgulanmıştır.

Bu çalışmada katıımcıların AMH konusuna bakış açılarını öğrenmek ve aile merkezli 
davranışlarını değerlendirmek amacıyla iki araç kullanılmıştır. Bunlardan ilki 27 sorudan oluşan ve sağlık çalışanlarının kendi aile merkezli uygulamalarını değerlendirmelerini sağlayan Hizmet Sağlayıcılar İçin Bakım Süreci Öıçeği'dir (BSÖ-HS) [16]. Bu ölçek CanChild Merkezi/ McMaster Üniversitesi'nin izniyle kullanılmıştır. Ölçeğin i) Kişiler Arası Duyarlılık (KAD) ii) Genel Bilgi Sağlama (GBS), iii) Çocuk Hakkında Özel Bilgi Paylaşma (ÖBP), ve iv) Kişilere Saygıyla Davranma (KSD) olmak üzere dört alt ölçeği bulunmaktadır. Katıımcılar, yaptıkları uygulamaları göz önünde bulundurarak sorulan sorulara 7'li Likert skalasından (0: Hiç - 7: Çok büyük ölçüde) birini işaretleyerek cevap vermektedir. Sonrasında alt ölçeklerin puanlarının ortalaması hesaplanmaktadır. Yüksek puan daha aile merkezli uygulamaları ifade etmektedir.

Çalışmada kullanılan diğer araç ise, 19 sorudan oluşan ve sağlık çalışanlarının AMH hakkındaki görüşlerini ortaya koymak üzere kullanılan Aile Merkezli Bakım Hakkında Görüşlerin Değerlendirilmesi anketidir [15]. Ankette, bu yaklaşımın olumlu ve olumsuz yönlerine ilişkin 6 ifade, bu yaklaşım hakkında bilgi düzeyi ve yeterlilik hakkında 3 ifade, yöntemin gerekliliği ve önemiyle ilgili 5 ifade ve uygulanabilirliğine ilişkin 3 ifade yer almaktadır. Katılımcıların ifadelere katılıp katılmadıklarını belirtmek için 5'li Likert ölçeğinden (1: tamamen katılıyorum - 5: hiç katılmıyorum) birini işaretlemeleri istenmektedir. Ankette yer alan son iki soru ise katılımcıların görüşlerini daha iyi anlamaya yönelik açık uçlu olarak hazırlanmış sorulardır. Bu soruların cevapları alındıktan sonra kodlanmış ve benzer cevaplar gruplandırılmıştır.

\section{İstatistiksel analiz}

Verilerin analizi SPSS 11.0 paket programından yararlanılarak yapılmıştır. Sayısal değişkenler ortalama \pm standart sapma şeklinde, kategorik değişkenler ise frekans ve yüzde ile ifade edilmiştir. Katılımcıların cinsiyet ve deneyim yılları bağımsız değişken olarak kullanılmış, cinsiyet ve deneyim yıllarına göre verilen sonuçlar karşılaştııılmıştır. Cinsiyet ve kategorize edilmiş deneyim yılı ( 1 yıldan az ve 1 yıl ve üstünde deneyim) bağımsız grup $t$ test yöntemi ile değerlendirilmiştir. Karşılaştırma $p$ değerinin 0,05 'in altında olması istatistiksel anlamlılık olarak kabul edilmiştir. Katılımcıların açık uçlu sorulara verdiği yanıtlardan ortak kavramlar belirleyerek kodlamalar yapılmıştır. Son olarak, tekrarlayan temalar gruplandırılıp içerik analizinin son hali elde edilmiştir.

\section{Bulgular}

Çalışmaya dil ve konuşma terapisi bölümünde eğitim alan 84 öğrenci katılmıştır. Katılımcıların cinsiyet ve alandaki deneyim süreleri Tablo 1'de sunulmuştur.

Katılımcıların BHÖ-HS puanları cinsiyet ve deneyim yıllarına göre karşılaştııılmıştır. BSÖ-HS ölçeğinin alt ölçeklerinin puanları değerlendirildiğinde katılımcıların kendilerini en yüksek puanladıkları alan Kişiler Arası Duyarlııı iken, Özel Bilgi Paylaşma alanı kendilerine en düşük puan verdikleri alan olmuştur. Katılımcıların BSÖ-HS ölçeği alt ölçek puanları ise Tablo 2'de sunulmuştur. Katılımcıların BSÖHS puanları cinsiyet ve deneyim yıllarına göre değerlendirilmiştir. Cinsiyete göre puanlar arasında istatistiksel olarak anlamlı bir fark bulunmamıştır (KAD için $t(82)=0,27, p>0,05$, $\mathrm{KSD}$ için $\mathrm{t}(82)=0,21, p>0,05$, ÖBP için $\mathrm{t}(82)=-$ $0,63, p>0,05$, GBS için $\mathrm{t}(82)=0,01, p>0,05)$. Katılımcılar kişi sayısı nedeniyle deneyimi bir yılın altında olanlar (lisans öğrencileri:52) ve bir yıl ve üstünde olanlar (yüksek lisans/ doktora öğrencileri:32) şeklinde iki gruba ayrıldığında, dört alt ölçekte de, deneyimi fazla olan katılımcıların puanları, deneyimi az olan katılımcılardan istatistiksel olarak daha yüksek olarak bulundu (Tablo 2).

Öğrencilerin Aile Merkezli Bakım Hakkında Görüşlerin Değerlendirilmesi anketinde yer alan ifadelere ne derece katıldıklarını ya da katılmadıklarını gösteren veriler Tablo 3'te sunulmuştur.

Son olarak da katılımcıların aile merkezli uygulamalar konusunda sorulan açık uçlu sorulara verdikleri yanıtlardan oluşturulan kavramlar Tablo 4'de sunulmuştur. 
Tablo 1. Katılımcıların özellikleri

\begin{tabular}{cl}
\hline Cinsiyet & $\mathrm{n}(\%)$ \\
\hline Kadın & $68(\% 80,9)$ \\
Erkek & $16(\% 19,1)$ \\
Alanda deneyim süresi & \\
Bir yılın altında & $52(\% 61,9)$ \\
Bir yıl & $8(\% 9,5)$ \\
İki yıl & $8(\% 9,5)$ \\
Üç yıl & $7(\% 8,3)$ \\
Dört yıl & $9(\% 10,7)$ \\
\hline
\end{tabular}

Tablo 2. Dil ve konuşma terapisi öğrencilerinin Hizmet Sağlayıcılar İçin Bakım Süreci Ölçeği (BSÖHS) puanları

\begin{tabular}{|c|c|c|c|c|}
\hline Alt ölçekler & $\begin{array}{l}\text { Tüm katılımcılar } \\
(\mathrm{n}: 84)\end{array}$ & $\begin{array}{l}\text { Deneyim } \\
<1 \mathrm{yll}(\mathrm{n:52})\end{array}$ & $\begin{array}{l}\text { Deneyim } \\
\geq 1 \text { yll }(\mathrm{n}: 32)\end{array}$ & $t_{(82)}$ \\
\hline Kişiler Arası Duyarlılık (KAD) & $5,75 \pm 0,58$ & $5,42 \pm 0,36$ & $6,29 \pm 0,28$ & $-11,70^{* * *}$ \\
\hline Kişilere Saygıyla Davranma (KSD) & $5,63 \pm 0,65$ & $5,18 \pm 0,29$ & $6,36 \pm 0,34$ & $-16,95^{* * *}$ \\
\hline $\begin{array}{l}\text { Özel Bilgi Paylaşma } \\
\text { (ÖBP) }\end{array}$ & $5,18 \pm 0,69$ & $4,78 \pm 0,46$ & $5,84 \pm 0,46$ & $-10,29^{* * * *}$ \\
\hline $\begin{array}{l}\text { Genel Bilgi Sağlama } \\
\text { (GBS) }\end{array}$ & $5,32 \pm 0,75$ & $4,83 \pm 0,42$ & $6,13 \pm 0,38$ & $-14,18^{* * *}$ \\
\hline
\end{tabular}


Tablo 3. Dil ve konuşma terapisi öğrencilerinin Aile Merkezli Bakım Hakkında Görüşlerin Değerlendirilmesi Anket'inde verilen ifadelere katılma durumunun dağılımı

\begin{tabular}{|c|c|c|c|c|c|}
\hline İfadeler & $\begin{array}{l}\text { Kesinlikle } \\
\text { Katılıyorum }\end{array}$ & Katılıyorum & Emin değilim & Katılmıyorum & $\begin{array}{l}\text { Kesinlikle } \\
\text { Katılmıyorum }\end{array}$ \\
\hline $\begin{array}{l}\text { AMH sağlık hizmetinin en ideal } \\
\text { şeklidir. }\end{array}$ & $17(\% 20,2)$ & $36(\% 42,9)$ & $22(\% 26,2)$ & $7(\% 8,3)$ & $2(\% 2,4)$ \\
\hline $\begin{array}{l}\text { Geleneksel yöntem ile } \\
\text { kıyaslandığında AMH ailelerin ve } \\
\text { çocuğun memnuniyetini artıracaktır. }\end{array}$ & $32(\% 38,1)$ & $30(\% 35,7)$ & $18(\% 21,4)$ & $4(\% 4,8)$ & $0(\% 0)$ \\
\hline $\begin{array}{l}\text { Geleneksel yöntemler yerine AMH } \\
\text { uygulanması gerektiğine inanıyorum. }\end{array}$ & $33(\% 39,3)$ & $30(\% 35,7)$ & $16(\% 19,0)$ & $3(\% 3,6)$ & $2(\% 2,4)$ \\
\hline $\begin{array}{l}\text { AMH, ailenin gözündeki 'sağlık } \\
\text { personeli' algısını olumsuz } \\
\text { etkileyecektir. }\end{array}$ & $0(\% 0)$ & $7(\% 8,3)$ & $23(\% 27,4)$ & $35(\% 41,7)$ & $19(\% 22,6)$ \\
\hline $\begin{array}{l}\text { AMH uygulanması sağlık personelinin } \\
\text { iş yükünü artıracaktır. }\end{array}$ & $0(\% 0)$ & $10(\% 11,9)$ & $25(\% 29,8)$ & $29(\% 34,5)$ & $20(\% 23,8)$ \\
\hline $\begin{array}{l}\text { Bu yaklaşım tedaviyi planlamada } \\
\text { ailenin katılımını da gerektirdiğinden } \\
\text { tedavi sonuçları daha olumlu } \\
\text { olacaktır. }\end{array}$ & $32(\% 38,1)$ & $34(\% 40,5)$ & $14(\% 16,7)$ & $4(\% 4,8)$ & $0(\% 0)$ \\
\hline $\begin{array}{l}\text { Ailelerin hastalıklar ve tedavi } \\
\text { hakkında bilgi düzeyinin } \\
\text { yetersiz olması bu yaklaşımın } \\
\text { uygulanabilirliğini kısıtlayacaktır. }\end{array}$ & $27(\% 32,1)$ & $44(\% 52,4)$ & $12(\% 14,3)$ & $1(\% 1,2)$ & $0(\% 0)$ \\
\hline AMH hakkında bilgi sahibiyim. & $39(\% 46,4)$ & $35(\% 41,7)$ & $8(\% 9,5)$ & $2(\% 2,4)$ & $0(\% 0)$ \\
\hline $\begin{array}{l}\text { AMH verme konusunda kendimi } \\
\text { yeterli hissediyorum. }\end{array}$ & $33(\% 39,3)$ & $37(\% 44)$ & $11(\% 13,1)$ & $3(\% 3,6)$ & $0(\% 0)$ \\
\hline $\begin{array}{l}\text { Ailelerin çocuklarının sağlığı ve } \\
\text { tedavisi konusunda karar vermede } \\
\text { istedikleri ölçüde yer almaları } \\
\text { gerektiğini düşünüyorum. }\end{array}$ & $12(\% 14,3)$ & $33(\% 39,3)$ & $30(\% 35,7)$ & $9(\% 10,7)$ & $0(\% 0)$ \\
\hline $\begin{array}{l}\text { Tedaviyi planlamada ailelerin } \\
\text { önceliklerinin, isteklerinin ve } \\
\text { tercihlerinin önemli olduğunu } \\
\text { düşünüyorum. }\end{array}$ & $22(\% 26,2)$ & $39(\% 46,4)$ & $19(\% 22,6)$ & $4(\% 4,8)$ & $0(\% 0)$ \\
\hline $\begin{array}{l}\text { Çocuğa sağlık hizmeti verilirken tüm } \\
\text { aile üyelerinin istedikleri ölçüde yer } \\
\text { almaları gerektiğini düşünüyorum. }\end{array}$ & $7(\% 8,3)$ & $27(\% 32,1)$ & $27(\% 32,1)$ & $17(\% 20,2)$ & $6(\% 7,1)$ \\
\hline $\begin{array}{l}\text { Her çocuk ve ailesine saygı } \\
\text { göstererek dinleyebileceğime, } \\
\text { farklı yönlerini yargılamadan } \\
\text { değerlendirebileceğime inanıyorum. }\end{array}$ & $32(\% 38,1)$ & $32(\% 38,1)$ & $17(\% 20,2)$ & $3(\% 3,6)$ & $0(\% 0)$ \\
\hline
\end{tabular}

*AMH: Aile merkezli hizmet 
Tablo 4. Dil ve konuşma terapisi öğrencilerinin aile merkezli uygulamalar konusunda açık uçlu sorulara verdiği cevaplar

\begin{tabular}{ll}
\hline “Aile merkezli hizmetin yararları ve olumlu yönleri nelerdir?” & Cevaplayan sayısı (n:61) \\
\hline Terapinin/tedavinin başarısının artması & 47 \\
Aile ile sorumluluğun paylaşılması ve ailenin sürece dahil olması & 15 \\
Aile ile olumlu ilişki/işbirliği sağlanması & 8 \\
Çocuk ve ailenin iletişiminin artması & 6 \\
Ailenin sağlık personeline güveninin artması & 5 \\
“Aile merkezli hizmetin olumsuz yönleri ya da uygulanmasındaki engeller & Cevaplayan sayısı (n:47) \\
nelerdir?” & 25 \\
Olumsuz bir yanı olmaması & 11 \\
Ailelerin yöntemi benimsememeleri/yöntemi olumsuz karşılamaları & 4 \\
Zaman kısıtıığının uygulamaya engel olması & 3 \\
Uygulamanın zor olması & 3 \\
Bilgi düzeyi düşük ailelerin bu yöntemi uygulayamayacağı & 2 \\
Diğer sağlık personellerinin yöntemi benimsememeleri/yöntemi olumsuz karşılamaları & 2 \\
\hline
\end{tabular}

\section{Tartışma}

Bu çalışma ile katılımcıların çoğunluğunun, aile merkezli hizmetin ideal hizmet şekli olduğu ve uygulanmasının gerekli olduğu, hasta ve personelin memnuniyetini artırıp tedavi sonuçlarına olumlu katkısı olacağı görüşüne katıldıkları ortaya konmuştur. Ayrıca katılımcıların çoğu AMH konusunda kendini bilgili ve yeterli hissediyordu. Katılımcılar bu yöntemin, aile ile sağlık çalışanının işbirliğini sağlayacağını ve çocuk ile ailenin iletişimini destekleyeceğini ifade etmişlerdi. Ancak ailelerin bu yöntemi benimsememeleri ya da olumsuz karşılamaları ise katılımcıların en sık belirttiği endişe olmuştu. Bu sonuçlar aile merkezli hizmetin doğru şekilde uygulanabilmesi için sadece sağlık çalışanlarının değil, ailelerin de konu hakkında farkındalığının artırılmasının gerekliliğini ortaya koymuştur.

Katıımcıların çok büyük bir kısmı, ailelerin bilgi düzeyinin yetersizliğini aile merkezli uygulamaların önündeki engellerden biri olarak görmekteydi. Bu çalışmanın sonuçları aynı anketin pediatri araştırma görevlilerine uygulandığı diğer bir çalışmanın sonuçları ile beraber değerlendirildiğinde [15], her iki çalışmada da ailelerin bilgi yetersizliği aile merkezli uygulamaların önünde engel olarak saptanmıştı. Öte yandan bu çalışma dil ve konuşma terapisi bölümü öğrencilerinin, pediatri uzmanlık eğitimi almakta olan araştırma görevlilerine kıyasla, aile merkezli uygulamaları daha çok benimsediklerini, bu uygulamalar konusunda kendilerini daha yetkin ve bilgili hissettiklerini düşündürmektedir. İki grup arasındaki bu farklılıköğrencilere verilen eğitimlerin içeriğinden ve ayrıca terapi hizmetlerinde aile merkezli uygulamaların daha fazla kabul görmüş olmasından kaynaklanmış olabilir.

Çalışmadan elde edilen BSÖ-HS ölçek puanları, uluslararası yazındaki BSÖ-HS ölçeği ile yapılan diğer çalışmaların sonuçlarıyla karşılaştırıldığında, puanların erken müdahale terapi alanında hizmet veren sağlık çalışanlarını değerlendiren araştırmalarda elde edilen puanlara benzer olduğunu görmekteyiz [1618]. Öte yandan bu çalışmadaki BSÖ-HS puanları, aynı kurumda ve pediatri uzmanlık eğitimi almakta olan hekimler ile yapılmış diğer çalışmanın puanlarından daha yüksek olarak bulunmuştur [15].

Bu çalışmada katııımcıların kendilerine Özel Bilgi Paylaşma ve Genel Bilgi Sağlama alanında en düşük puanları verdikleri belirlenmiştir. BSÖHS ölçeğindeki puan dağılımı araştırmalarda değişmekle beraber, özel ya da genel bilgi sağlama uluslararası yazında da çoğunlukla en düşük puanlanan alan olarak bildirilmiştir [4, 16, 18-20]. Bu bulgu, aile merkezli yaklaşımın yapıtaşlarından biri olan bilgi sağlama alanını, geliştirilmesi gereken bir alan olarak öne çıkarmıştır. 
Çalışmada BSÖ-HS puanları açısından kadın ve erkek katılımcılar arasında fark bulunmamakla birlikte, deneyimi daha fazla olan katılımcıların kendilerine aile merkezli uygulamalar konusunda, deneyimi daha az olan katılımcılara göre daha yüksek puanlar verdikleri ortaya konmuştur. Deneyim arttıkça aile merkezli davranış puanlarının artması, BSÖHS ölçeği kullanılarak yapılan diğer uluslararası araştırmalarda da saptanan bir durumdur [17, $19,20]$. Bu sonuç deneyim kazanmanın aile merkezli uygulamaları artırabileceğini, başka bir açıdan da deneyimli çalışanların bu uygulamalar konusunda kendilerini daha yetkin hissettiklerini düşündürmektedir.

Çalışmada kullanılan iki araç ile elde edilen sonuçlar bir arada değerlendirildiğinde, katıımcıların bilgi sağlama alanında diğer alanlara göre kendilerine daha düşük puanlar vermeleri, ailelerin bilgi düzeyinin az olduğunu düşünmeleri ve aile merkezli uygulamalar ile ailelerden olumsuz yanıt alabileceklerini düşünmeleri ile ilişkili olabilir. Öte yandan katılımcıların çoğunluğu aile merkezli uygulamaların gerekliliğine inanıyor, kendilerini AMH konusunda yeterli ve bilgili hissediyor ve ailelere saygıyla yaklaşabileceğini düşünüyordu. Katılımcıların BSÖ-HS'de Kişiler Arası Duyarlılık ve Kişilere Saygıyla Davranma alanlarında kendilerini daha yüksek puanlamaları bu sonuca paralel olarak değerlendirilebilir.

Aile merkezli uygulamalar çocuk sağlığı hizmetinde standart yaklaşım olarak kabul edilmektedir [21]. Bu yaklaşımın sağlık sistemlerine doğru şekilde entegre edilebilmesi için sağlık çalışanlarının bu konuya bakış açılarının ortaya konması ve aile merkezli davranışlarının değerlendirilmesi önem taşıyacaktır. Bu çalışma, dil ve konuşma terapisi bölümünde eğitim alan öğrencilerin aile merkezli hizmet konusundaki görüşlerini araştıran ve aile merkezli davranışlarını değerlendiren ilk çalışmadır.

Ancakçalışmanın sonuçları değerlendirilirken kısıtlılıkları da göz önünde bulundurulmalıdır. Bu çalışmanın en önemli kısıtıı̆ı̆ı BSÖHS ölçeğinin Türkçe geçerlilik ve güvenirlik çalışmasının henüz tamamlanmamış olmasıdır. Çalışmanın bir diğer kısıtlılığı ise tek merkezde yapılan bu çalışmanın sonuçlarının tüm Türkiye'deki Dil ve konuşma Terapisi Bölümü öğrencilerine genellenemeyecek olmasıdır.
Öte yandan, bu çalışma ile dil ve konuşma terapisi öğrencilerinin aile merkezli yaklaşımlar konusundaki görüşleri derinlemesine öğrenilmiş olup, yöntemin uygulanmasındaki engeller ortaya konmuştur. Profesyonel hayatının başında olan öğrencilerin aile merkezli uygulamalar hakkındaki görüşlerini, endişelerini ve uygulamaya engel teşkil ettiğini düşündükleri noktaları belirlemek ve onların hali hazırdaki uygulamalarını değerlendirmek hazırlanacak eğitim programları için önemli olacaktır. Bu nedenle bu çalışmanın sonuçları çocuk sağlığı ve erken müdahale alanında aile merkezli hizmetlerin yaygınlaşmasını hedefleyen eğitimciler, yöneticiler ve politika yapıcılar için yol gösterici olabilecektir.

Çıkar ilişkisi: Yazarlar çıkar ilişkisi olmadığını beyan eder.

\section{Kaynaklar}

1. Patient and family centered care. Institute for Patientand Family-Centered Care. Available at: https://www. ipfcc.org/about/pfcc.html. Accessed July 05, 2020

2. Committee on hospital care and institure for patientand family- centered care. Patient- and family-centered care and the pediatrician's role. Pediatr 2012;129:394404. https://doi.org/10.1542/peds.2011-3084

3. Kuhlthau KA, Bloom S, Van Cleave J, et al. Evidence for family-centered care for children with special health care needs: a systematic review. Acad Pediatr 2011;11:136-143. https://doi.org/10.1016/j. acap.2010.12.014

4. Raghavendra P, Murchland S, Bentley M, Wake Dyster W, Lyons T. Parents' and service providers' perceptions of family-centred practice in a community-based, paediatric disability service in Australia. Child Care, Health Dev 2007;33:586-592. https://doi.org/10.1111/ j.1365-2214.2007.00763.x

5. Hanna K, Rodger S. Towards family centred practice in paediatric occupational therapy: a review of the literature on parent-therapist collaboration. Austr Occup Ther J 2002;49:14-24. https://doi.org/10.1046/ j.0045-0766.2001.00273.x

6. Crais ER, Roy VP, Free K. Parents' and professionals' perceptions of the implementation of familycentered practices in child assessments. Am J Speech Lang Pathol 2006;15:365-377. https://doi. org/10.1044/1058-0360(2006/034)

7. McCormack J, McLeod S, Harrison LJ, McAllister L. The impact of speech impairment in early childhood: investigating parents' and speech-language pathologists' perspectives using the ICF-CY. J Commun Disord 2010;43:378-396. https://doi.org/10.1016/j. jcomdis.2010.04.009 
8. Pappas NW, McLeod S, McAllister L, McKinnon DH. Parental involvement in speech intervention: a national survey. Clin Linguist Phon 2008;22:335-344. https:// doi.org/10.1080/02699200801919737

9. Al Motlaq MA, Shields L. Family-centered care as a western-centric model in developing countries: luxury vercus necessity. Holist Nurs Pract 2017;31:343-347. https://doi.org/10.1097/HNP.0000000000000228

10. Shields L, Cavuşoğlu H, Pars H, Mamun AA. Measuring family-centred care: working with children and their parents in a Turkish hospital. Eur J Pers Cent Healthc 2015;3:327-333

11. Craft Rosenberg M, Kelley P, Schnoll L. Familycentered care: practice and preparation. Families in Society 2006;87:17-25. https://doi.org/10.1606/10443894.3480

12. Murray MM, Mandell CJ. Evaluation of a familycentered early childhood special education preservice model by program graduates. TECSE 2004;24:238249. https://doi.org/10.1177/02711214040240040501

13. Case Smith J, Sainato D, McQuaid J, Deubler D, Gottesman M, Taber M. IMPACTS project: preparing therapists to provide best practice early intervention services. Phys Occup Ther Pediatr 2007;27:73-90.

14. Scarinci N, Rose T, Cronan A, Lambertz K. Speech pathology student experiences and perceptions of working with parents in a Hanen it takes two to talk family-centred clinical placement. Speech, Language and Hearing 2018;21:132-141. https://doi.org/10.1080 /2050571X.2017.1329890

15. Zengin Akkus P, Ilter Bahadur E, Coskun A, Koken G, Karahan S, Ozmert EN. Family-centred service: perspectives of paediatric residents from a nonWestern country. Child Care, Health Dev 2020;46:275282. https://doi.org/10.1111/cch.12753

16. Woodside JM, Rosenbaum PL, King SM, King GA. Family-centered service: developing and validating a self-assessment tool for pediatric service providers. Children's Health Care 2001;30:237-252. https://doi. org/10.1207/S15326888CHC3003_5

17. Kang LJ, Palisano RJ, Simeonsson RJ, Hwang AW. Measuring family-centred practices of professionals in early intervention services in Taiwan. Child Care, Health Dev 2017;43:709-717. https://doi.org/10.1111/ cch. 12463

18. Jeglinsky I, Autti Rämö I, Brogren Carlberg E. Two sides of the mirror: parents' and service providers' view on the family-centredness of care for children with cerebral palsy. Care, Health Dev 2012;38:79-86. https://doi.org/10.1111/j.1365-2214.2011.01305.x

19. Dyke P, Buttigieg P, Blackmore AM, Ghose A. Use of the measure of process of care for families (MPOC-56) and service providers (MPOC-SP) to evaluate familycentred services in a paediatric disability setting. Care, Health Dev 2006;32:167-176. https://doi.org/10.1111/ j.1365-2214.2006.00604.x
20. Jeglinsky I, Autti Rämö I, Brogren Carlberg E. Professional background and the comprehension of family-centredness of rehabilitation for children with cerebral palsy. Care, Health Dev 2012;38:70-78. https://doi.org/10.1111/j.1365-2214.2011.01211.x

21. Committee on Hospital Care. American Academy of Pediatrics. Family-centered care and the pediatrician's role. Pediatrics 2003;112:691-697.

Etik kurul onayı: Bu çalışma Hacettepe Üniversitesi Etik Komisyonu tarafından 26.07.2019 tarih ve 700133 sayı ile uygun bulunmuştur.

\section{Yazarların makaleye olan katkıları}

P.Z.A. ve E.N.Ö. çalışmanın ana fikrini ve hipotezini kurgulamışlardır. P.Z.A., E.I.B. ve T.K. teoriyi geliştirmiş ve materyel metod bölümünü düzenlemişlerdir. Sonuçlar kısmınındaki verilerin değerlendirmesini P.Z.A. ve T.K. yapmışlardır. Makalenin tartışma bölümü P.Z.A. tarafından yazılmış, E.N.Ö. gözden geçirip gerekli düzeltmeleri yapmış ve onaylamıştır. Ayrıca tüm yazarlar çalışmanın tamamını tartışmış ve son halini onaylamıştır. 